\title{
Modification of gas diffusion layers properties to improve water management
}

\author{
Martin Tomas $^{1}\left(\right.$ Indro S. Biswas $^{2} \cdot$ Pawel Gazdzicki $^{2} \cdot$ Lucie Kullova $^{1} \cdot$ \\ Mathias Schulze ${ }^{2}$
}

Received: 25 May 2017/ Accepted: 19 September 2017/Published online: 22 September 2017

(c) The Author(s) 2017. This article is an open access publication

\begin{abstract}
In this paper we report an approach to improve water management of commercial GDLs by introducing hydrophobicity patterns. Specifically, line and grid patterns have been created in the MPL side by laser radiation. For an in-depth investigation of these modified GDLs the current density distribution was monitored during fuel cell operation. Additionally, the physical properties of these materials were investigated by a number of ex situ methods such as Fourier transform infrared microscopy, electrochemical impedance spectroscopy and water vapor
\end{abstract}

sorption. Furthermore, a comparison of the physical properties of the patterned GDLs with chemically modified GDLs (treated in $\mathrm{H}_{2} \mathrm{SO}_{4}$ and $\mathrm{H}_{2} \mathrm{O}_{2}$ ) is provided. Our results show a clearly improved homogeneity of current density distribution of the patterned GDLs compared to untreated GDLs. This observation is likely due to a reduced local hydrophobicity which facilitates water diffusion along the flow field of the fuel cell. However, performance of the fuel cell was not affected by the MPL irradiation.
Martin Tomas

mtomas@ntc.zcu.cz

1 University of West Bohemia, Univerzitni 8, 30614 Pilsen, Czech Republic

2 German Aerospace Center (DLR), Institute of Engineering Thermodynamics, Pfaffenwaldring 38-40, 70569 Stuttgart, Germany 


\section{Graphical Abstract}
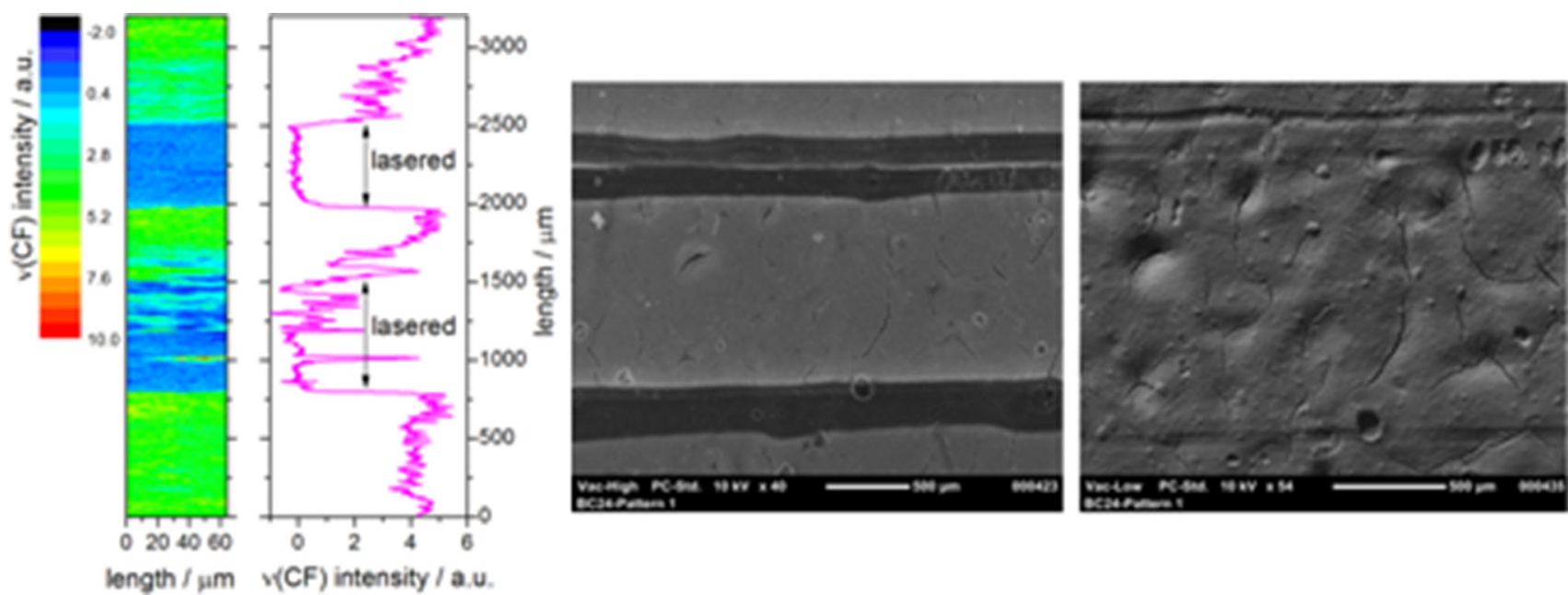

Keywords Fuel cell · GDL · Water management ·

Performance $\cdot$ PTFE $\cdot$ Laser patterning

\section{Introduction}

In a polymer electrolyte membrane fuel cell (PEMFC) the gas diffusion layer (GDL) is used for proper distribution of reactants to the catalyst layer and for the water management within the membrane electrode assembly (MEA) making the GDL a key component responsible for appropriate and continuous fuel cell operation $[1,2]$. The GDL is typically divided into two parts-the macroscopically porous GDL backing and the microporous layer (MPL) [3]. Both parts are treated with poly(tetrafluoroethylene) (PTFE) to obtain specific hydrophobicity needed for fuel cell operation. Flooding of the active catalyst layer (CL), where the reactions take place [4] is avoided by transporting the water away from the reaction layer due to the hydrophobic behavior of GDL $[5,6]$. Water produced inside the fuel cell can flood the pores of GDL and decrease the gas permeability of the layer promoting fuel starvation [7-9]. Moreover, excess water can drag the platinum particles from the $\mathrm{CL}$, so that the electrochemical processes efficiency is lowered [10]. On the other hand, a drying out of the membrane has to be avoided to assure adequate ionic conductivity [11]. Furthermore, the MPL provides an effective current collection and a smooth, continuous interface between GDL and CL [12] reducing the ohmic losses in the fuel cell and enhancing chemical and mechanical stability of the CL and the membrane [1].

Within this paper we address the possibility of improving GDL properties by locally changing its hydrophobic properties by patterning it via laser radiation, i.e., by locally burning PTFE. The main idea of this modification was the fact that water management can be positively affected by varying the PTFE content in the GDL [11, 13]. In recent studies the non-homogeneous distribution of PTFE was investigated $[11,14,15]$. It was concluded that the appropriate ratio of hydrophobic and hydrophilic regions can improve the water management in a fuel cell [15].

We have also considered a treatment of the samples with sulfuric acid or hydrogen peroxide to affect the PTFE coating of carbon fibers [16] leading to a severe loss of hydrophobicity as reported by Borup et al. [17]. Then we have compared laser patterned GDLs with chemically treated samples to evaluate the differences between these two methods of the PTFE content modification.

\section{Experimental}

\section{Sample preparation}

To prepare a hydrophilic laser pattern, pristine GDLs (SGL Carbon Sigracet 24BC) were exposed to laser of $350 \mathrm{~mW}$ power (green laser, $532 \mathrm{~nm}$ ). Simple patterns (parallel lines or grid) of burned channels were created by moving the laser with about $1 \mathrm{~cm} \mathrm{~s}^{-1}$ over the sample, see Fig. 1. Due to its more homogeneous structure in this study only the MPL side of the GDL was laser treated. For the assembly of the treated GDLs in a fuel cell the single channel flow field was oriented perpendicular to the pattern.

For chemical modification the GDL samples were exposed to $1 \mathrm{M}$ hydrogen peroxide or $1 \mathrm{M}$ sulfuric acid solutions for $24 \mathrm{~h}$ in $80^{\circ} \mathrm{C}[16,18]$. These modified 


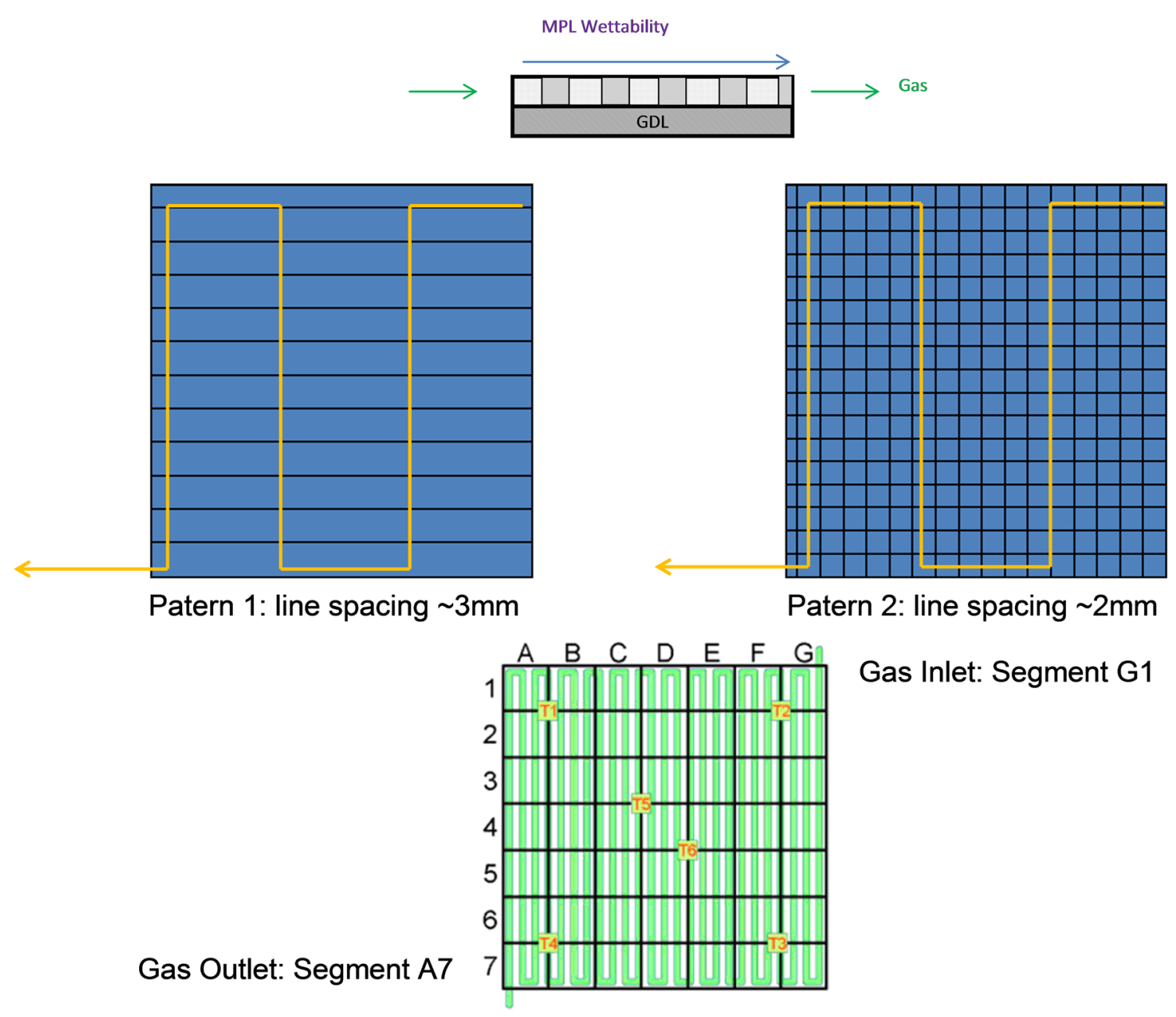

Fig. 1 Hydrophobicity patterns performed with a focused laser beam. The green pattern is a scheme of the flow field of the segmented board, the temperature sensors and the $7 \times 7$ segments are labeled (detailed description in [19])

samples were immersed in deionized (DI) water to remove the residues of solution. After that the samples were dried in a temperature chamber for $2 \mathrm{~h}$ at $80{ }^{\circ} \mathrm{C}$.

\section{Fuel cell test conditions}

To test the pristine and patterned GDLs in fuel cell operation we used a $5 \times 5 \mathrm{~cm}^{2}$ cell with a single serpentine flow field. The cell was operated in galvanostatic mode with $\mathrm{H}_{2}$ and air in co-flow configuration. The cell operation temperature was $80^{\circ} \mathrm{C}$. Above $0.3 \mathrm{~A} \mathrm{~cm}^{-2}$ the $\mathrm{H}_{2}$ stoichiometry and oxygen stoichiometry was set to 1.5 and 2.0, respectively. The relative humidity (RH) was controlled by the bubbler temperature and was set to $50 \%$. The gas outlet absolute pressure was 1.5 bar.

A DLR home-made segmented board with $7 \times 7$ segments and $5 \times 5 \mathrm{~cm}^{2}$ was used for current density distribution monitoring $[19,20]$. The board was installed at the anode side. In Fig. 1 the scheme of the flow field with the indicated segments is plotted.
The segmented board consists of current collector segments placed on the surface of an epoxy-glass resin matrix. For the local current measurement a resistor array is integrated in the printed circuit board. The gas supply is mounted from the back side of the measuring board. The back layer of the board is connected by conducting wires with the front (flow field) which is divided into segmented cells to avoid lateral conduction along the flow field. The current and voltage signals from the segmented board are measured with a multiplexer and a digital multimeter; the data acquisition system of the segmented cell is independent of the control system of the fuel cell test bench. The width of the channel and the land was 1.1 and $0.8 \mathrm{~mm}$, respectively. The inlet is at segment G1, whereas segment A7 is the location of the gas outlet (see Fig. 1).

\section{Ex situ techniques}

For local Fourier transform infrared (FTIR) analysis of PTFE in the laser patterned MPL a Bruker Vertex 80v 
FTIR spectrometer coupled with a Bruker Hyperion 3000 microscope was used. A typical FTIR microscopy image [18] consists of an array of numerous measuring points each measured in the attenuated total reflection (ATR) mode using a conical Ge crystal (diameter of the tip is $100 \mu \mathrm{m})$ that is pressed onto the sample for good mechanical contact, i.e., high signal to noise ratio. For high lateral resolution $(1 \mu \mathrm{m})$ each measuring position $\left(32 \times 32 \mu \mathrm{m}^{2}\right)$ was detected with a liquid nitrogen cooled mercury-cadmium-telluride focal plane array (FPA) detector consisting of $64 \times 64$ pixels. Typical spectra were recorded with $2 \times 2$ binning $(32 \times 32$ superpixels) in the range of $600-4000 \mathrm{~cm}^{-1}$ with $4 \mathrm{~cm}^{-1}$ resolution and consist of typically 32 accumulated scans.

For detailed investigation of surface structure and morphology, the samples were scanned with a Jeol JCM5000 electron microscope.

The electrical properties were studied with electrochemical impedance spectroscopy (EIS) using a Solartron $1287 \mathrm{~A} / 1260$ facility. This method can be used to determine the dependency of electrical impedance on frequency of the applied electrical field. To ensure a proper contact between the sample and the electrode a special sample holder was developed and liquid electrodes (mercury) were used.

Through-plane conductivity of pristine, chemically modified and irradiated GDLs was studied in frequency range from $0.1 \mathrm{~Hz}$ to $20 \mathrm{MHz}$ at ambient conditions. Excitation amplitude was set to $10 \mathrm{mV}$.

The thermal stability of the samples was investigated in the temperature range from 25 to $1000{ }^{\circ} \mathrm{C}$ with a thermogravimetry analyzer (MTGA, Q500) in a nitrogen atmosphere; the heating rate and the nitrogen flow were set to $10{ }^{\circ} \mathrm{C} \mathrm{min}{ }^{-1}$ and $40 \mathrm{ml} \mathrm{min}{ }^{-1}$, respectively. During the temperature increase, it is possible to detect the thermal decomposition of materials and the content of inert residues. Thermal stability measurements of GDLs provide information which can be relevant for MEA preparation processes such as hot pressing [21].

The absorption and desorption processes related to water uptake were studied with dynamic gravimetric water sorption analyzer (DVS ET, Surface Measurement Systems). During this measurement the mass of the sample is monitored and the humidity in the measuring cell is dynamically regulated. The difference in absorption and desorption processes is represented by sorption isotherm and its hysteresis.

\section{Results and discussion}

In this section first the characterization of the laser patterned GDLs by FTIR microscopy and scanning electron microscopy (SEM) is discussed. Secondly, the influence of the laser patterning on fuel cell performance is analyzed based on the local current density distribution. To better understand the behavior of the laser patterned layers the physical properties of these samples are compared with those of chemically modified GDLs.

By means of laser radiation simple patterns of straight lines (pattern 1) and grid (pattern 2) were created on the MPL surface (see Fig. 1). The distance between lines was approximately $2-3 \mathrm{~mm}$ and the line thickness was about $0.5 \mathrm{~mm}$. The patterns were created by horizontal motion of the laser beam. The effect of the irradiation on the MPL with a laser beam is basically identical with a highly local heating of the material. This leads to burning, carbonization and/or evaporation of the surface components. It has been observed, that irradiation of the microporous layer media with $350 \mathrm{~mW}$ at $532 \mathrm{~nm}$ almost instantly burns holes or trenches into the material.

For local FTIR imaging of PTFE in the MPL the integrals of the $\mathrm{C}-\mathrm{F}_{2}$ stretch vibrations were analyzed in the spectral range $1100-1300 \mathrm{~cm}^{-1}$, resembling the presence of PTFE [18]. Typical FTIR spectra of a non-lasered (high $\mathrm{C}-\mathrm{F}$ intensity) and a lasered (low $\mathrm{C}-\mathrm{F}$ intensity) region of the MPL are provided in Fig. 2a.

Figure $2 b$, c show, respectively, the FTIR microscopy image and a corresponding line scan of the MPL side (the signal corresponds to peak areas of the $\mathrm{CF}_{2}$ stretch vibrations in the range $1100-1300 \mathrm{~cm}^{-1}$ ), which has been locally irradiated (two parallel lines corresponding to the blue color in the spectroscopic image) according to the procedure described above. Evidently within the burned lines the $\mathrm{C}-\mathrm{F}_{2}$ vibrational intensity is virtually zero, while it is high outside the lines.

In this context it is noted that in some measurements an increased abundance of PTFE is observed between two lines compared to a pristine sample (Fig. 3). It can be speculated that parts of the evaporated or burned PTFE has been redeposited during the laser treatment.

The surface of the irradiated GDLs was scanned with the electron microscope (Fig. 2) whereby two imaging methods were used. In Fig. 2d the imaging mode based on the detection of secondary electrons is used. The burned lines are clearly visible as dark regions. However, the GDL backing is not recognizable: this fact suggests that only a small surface region of the MPL is affected. The same sample was scanned using the method based on backscattered electrons detection (Fig. 2e). This method provides additional information about the GDL surface. Obtained image shows the superficial deterioration of the MPL caused by laser irradiation.

For the performance tests the two patterns were prepared out of an MPL for $25 \mathrm{~cm}^{2}$ single cell and were mounted on the cathode side. The line patterned specimen was mounted in the test cell with the grafted trenches orthogonally to the 


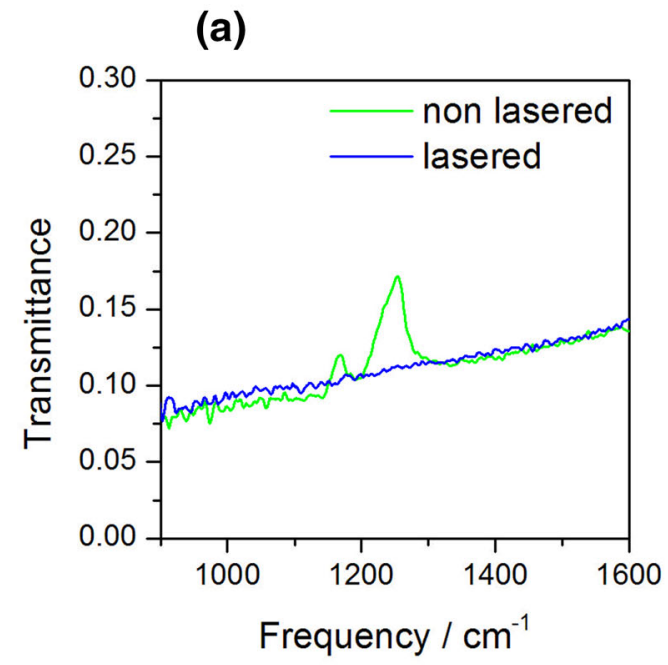

(d)

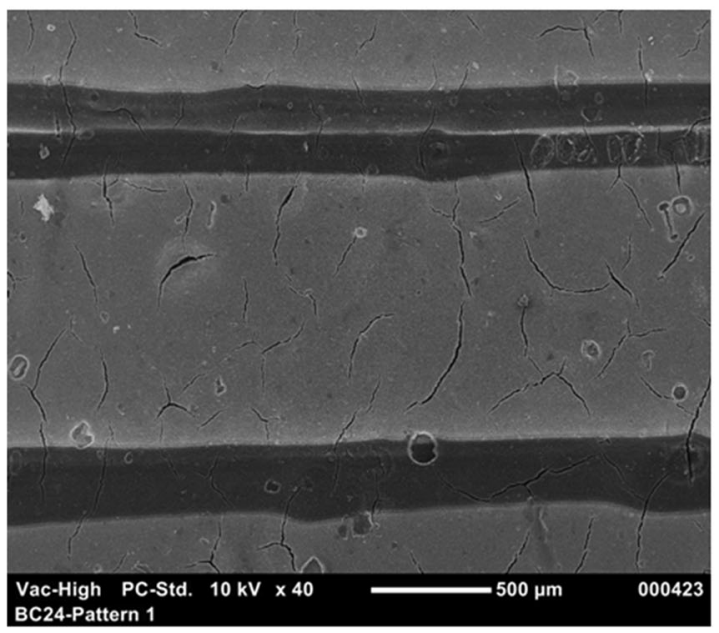

Fig. 2 a FTIR spectra of the C-F stretch of laser burned and pristine MPLs. b FTIR image of the MPL locally treated with laser radiation. The color scale corresponds to integrated $\mathrm{C}-\mathrm{F}$ intensities. c FTIR line

overall flow field channels; for the grid pattern, the mounting direction was irrelevant. To assembly the MEA a commercial catalyst coated membrane (Johnson Matthey) was used. The cell was equipped with a DLR home-made segmented board to monitor the current density distribution.

At the beginning of the tests, performance curves of MEAs containing either the pristine GDL or the modified GDLs were measured. As observed in Fig. $4 \mathrm{~b}$, the performance of the fuel cell is not significantly affected by laser (b)
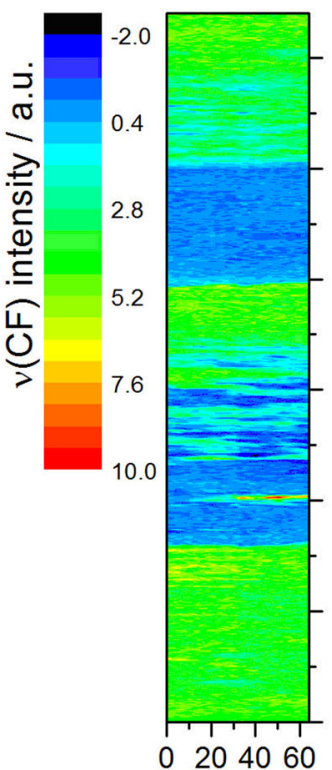

length / $\mu \mathrm{m}$

(c)

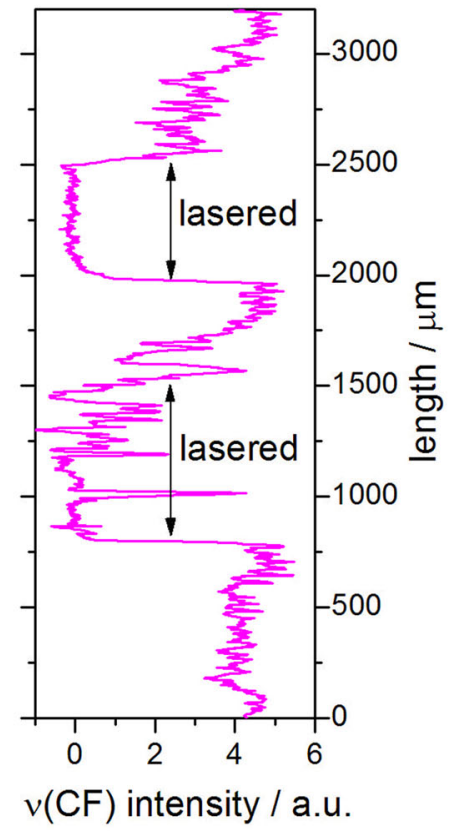

(e)

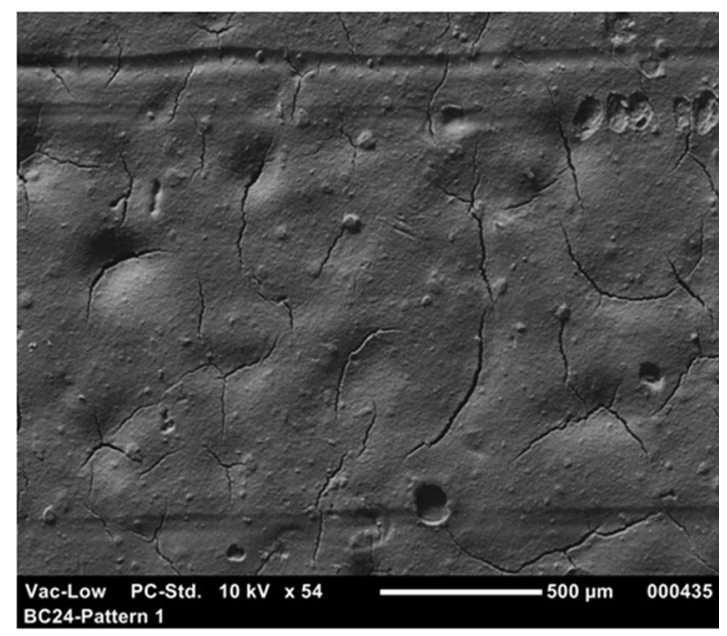

scan over the two laser burned lines from panel b. SEM images of partially irradiated MPL recorded using $\mathbf{d}$ secondary electrons and e backscattered electrons

irradiation of GDLs under the chosen experimental conditions.

However, the cells with the different GDLs exhibit substantial differences regarding current density distributions. In Fig. 4a current density distributions recorded at different loads using pristine and patterned MPLs are shown. In the provided test the humidification of gases was $50 \%$ RH. Evidently, in the case of the pristine MPL the maximum current density is located clearly in the gas inlet region. At the cell outlet the performance is worst. The 
Fig. 3 FTIR line scan of the PTFE distribution measured between two lines of the laser pattern (see Fig. 1) in the MPL. Plotted is the integrated intensity of the $\mathrm{CF}_{2}$ stretch vibrations $\left(1100-1350 \mathrm{~cm}^{-2}\right)$ versus distance. The red line indicates the average $\mathrm{CF}_{2}$ stretch vibration integrated intensity of non-modified MPL

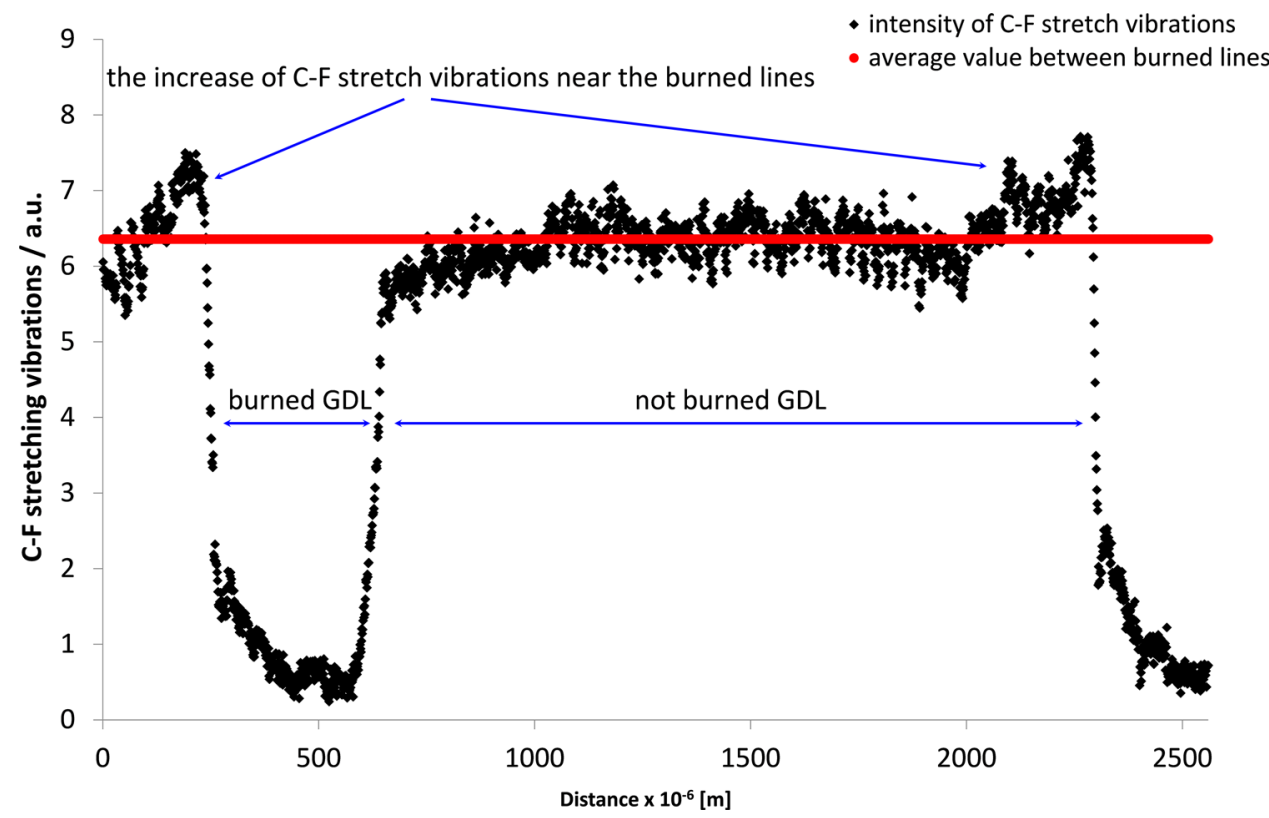

homogeneity of the distribution, represented by the value $a$ (percentage of values that are within $\pm 20 \%$ of average), is around $a=60-80 \%$.

On the other hand, the current density distributions measured with the patterned MPLs show a maximum shifted to the centre of the cell with a significantly improved homogeneity with $a=90-100 \%$.

The improved homogeneity of the current density distribution along the flow field is clearly related to a decreased local hydrophobicity $[11,22]$. Thereby, both tested patterns behave similarly suggesting that in the used co-flow configuration only a small change of MPL's hydrophobicity is sufficient to obtain significantly more homogeneous current density distribution. In this context, it may be stated that a more homogeneous current density distributions would likely extend the life time of the fuel cell, as mentioned in [23, 24]. It should be noted that the water management is influenced by many effects, e.g., water removal due to high reactant flow rate [25] or GDL oxidation by substances as hydrogen peroxide and sulfuric acid degrades fuel cell operation [16, 26].

The electrical properties of the samples were measured using EIS. Thereby, an increase of electrical conductivity was observed probably due to the loss of the electrically insulating PTFE [27] during the immersion of GDLs in solutions. Experiments related to GDL resistivity were carried out using mercury electrodes to obtain renewable, uniform and smooth interface between the GDL and the electrode. The experimental setup allows the through-plane measurement under ambient pressure. The electrical properties of GDL depend on applied pressure and the resistivity can radically decrease during the compression in fuel cell, because the pores in the GDL without applied pressure are filled with air [28, 29]. Our method can be used to distinguish the samples with various content of PTFE (see Fig. 5a). Moreover, liquid electrode assures lower contact resistance compared to solid electrode. The electrical conductivity was calculated using the approximation (derived from [30]).

$\sigma=\frac{h}{R \pi r^{2}}$

where $h$ is the thickness of the GDL, $R$ is the resistivity and $r$ is the radius of the mercury electrode (this formula is valid for $r \gg h$ ). As shown in Fig. 5a the electrical conductivity significantly increases in case of samples affected by sulfuric acid and hydrogen peroxide solutions. The surface of these samples is meant to be more influenced than the surface of irradiated samples. This fact is supported by other results obtained using FTIR and TGA methods.

The results of thermal stability measurement show significantly faster decomposition of chemically modified GDLs (Fig. 5b) compared to pristine and lasered samples. The steep decrease of sample mass between 500 and $600{ }^{\circ} \mathrm{C}$ is related to PTFE decomposition [31, 32]. Rapid mass loss above $600{ }^{\circ} \mathrm{C}$ can be caused by structural deterioration of GDL or change of functionalization of the carbon fiber surface (formation of the carboxyl groups). Solutions used for chemical modification may influence the carbon fibers and the diffusion layer becomes less stable during the temperature increase. Diluted solutions can oxidize carbon fibers [16] and this corrosion process results in formation of substances such as phenol and carboxyl groups [17].

The samples were also investigated with respect to water vapor sorption and desorption (see Fig. 5c). This measurement can be used for the determination of a volume density of 


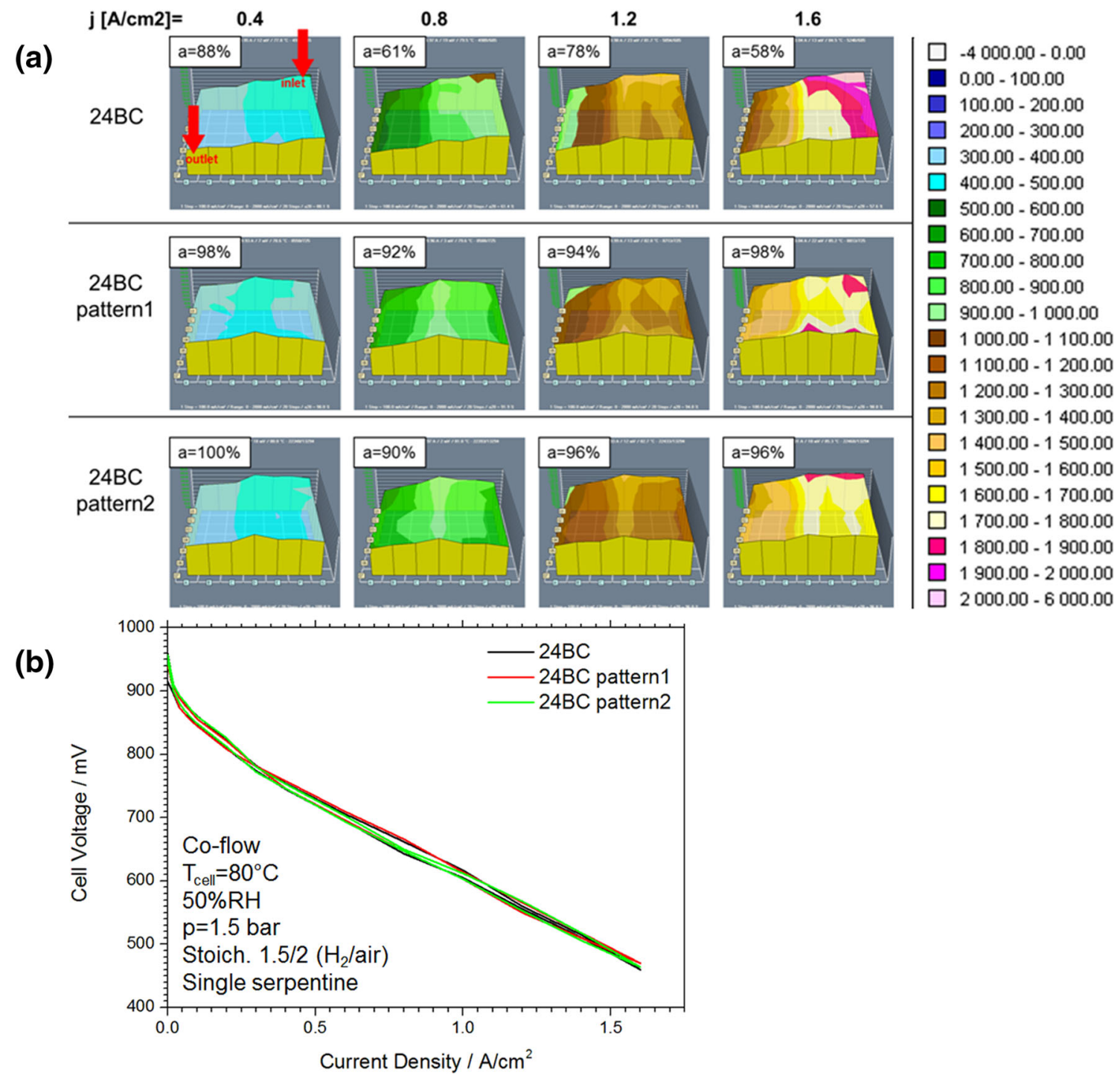

Fig. 4 Current density distributions and polarization curves of MEAs with pristine and modified GDLs measured at $50 \% \mathrm{RH}$. a Current density distributions for the pristine GDL, pattern 1 and pattern 2 (compare Fig. 1) recorded at the indicated current densities. The value $a$ is the percentage of values that are within $\pm 20 \%$ range of

hydrophobic regions. Water vapor is stored in the hydrophilic regions and the increase of the sample mass can be detected. Thereby the amount of sorbed water is represented by the hysteresis. In case of pristine GDL the volume density of hydrophobic regions is larger than in case of chemically modified or irradiated GDLs leading to a narrow hysteresis. Similarly, the sample treated by sulfuric acid shows a small hysteresis suggesting virtually no impact of this treatment on the hydrophobicity. In contrast, hydrogen peroxide affects the PTFE coating leading to a severe volume density loss of the hydrophobic regions and a large hysteresis. A significant increase of sample mass was measured for irradiated samples pointing at their reduced hydrophobicity compared to other samples and supporting FTIR analysis where a loss of average. Higher values mean higher homogeneity. The current density values (color scale) are in $\mathrm{mA} \mathrm{cm} \mathrm{cm}^{-2}$. The gas inlet and outlet are labeled by red arrow. The bottom panel b shows the corresponding performance curves

hydrophobic PTFE was clearly observed. Since the lasered area is larger in pattern 2 than in pattern 1, its hysteresis is larger accordingly (see Fig. 5c). The possible explanation is that the partly burned MPL strongly affected a water uptake of irradiated GDL and the water diffusion was facilitated $[11,33]$.

\section{Conclusion}

The GDL Sigracet 24BC was irradiated with laser beam and simple patterns of burned lines were created. The thermal, electrical and sorption properties were studied for pristine chemically modified and laser irradiated samples. 
(a)

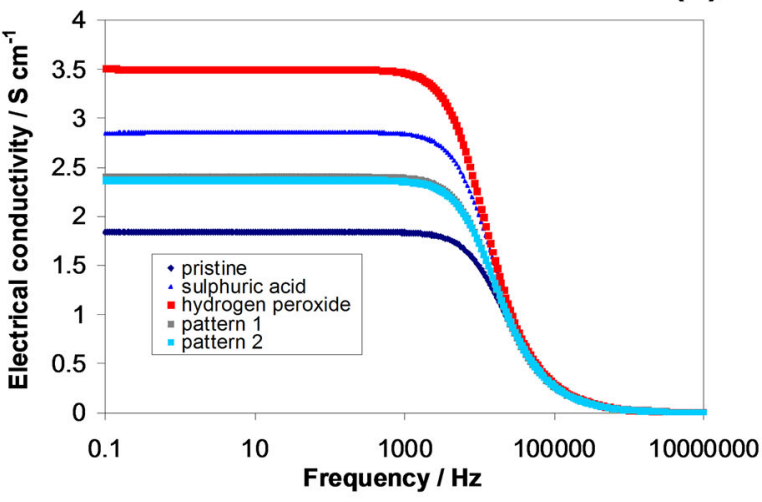

(b)

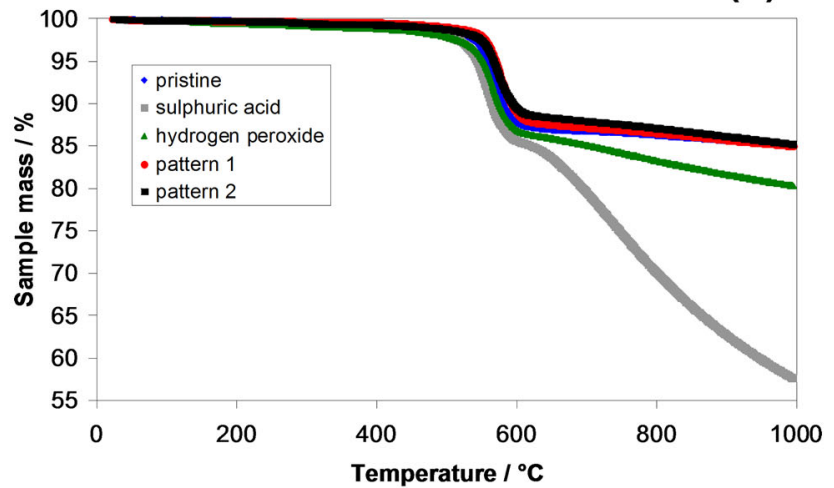

(c)

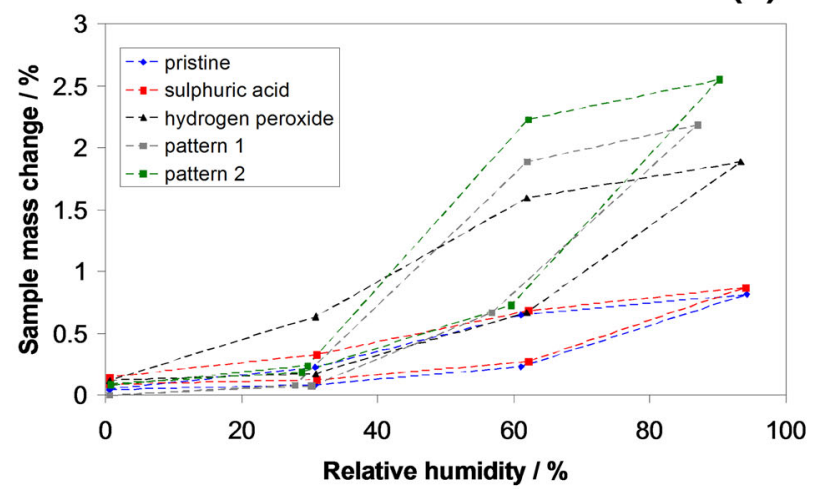

Fig. 5 a Electrical conductivity of pristine and chemically modified GDLs Sigracet 24BC, b the thermal stability (TGA measurement) of pristine and modified GDLs $\mathbf{c}$ water vapor sorption and desorption of investigated GDLs

The performance test of MEA containing irradiated GDL was conducted and the current density distribution was investigated. Under the operation conditions used, the results show significantly more homogeneous current density distribution when patterned GDLs were used compared to pristine GDLs. This is likely due to an improvement of the water management changing local hydrophobicity leading to a facilitation of water diffusion and removal along the flow field. An influence of the laser irradiation on the performance of the fuel cell was not observed.

For detailed analysis of the physical properties of the patterned GDLs, further GDLs were modified by sulfuric acid and hydrogen peroxide for comparison. Electrical conductivity of chemically modified samples increased with respect to PTFE content decrease. Water sorption of the sample exposed to hydrogen peroxide increased due to the loss of the density of hydrophobic regions (the impact of sulfuric acid was weak). The thermal stability measurement of the chemically modified GDLs showed rapid decrease of sample mass during heating.

Acknowledgements The result was developed within the CENTEM project, reg. no. CZ.1.05/2.1.00/03.0088, co-funded by the ERDF as part of the Ministry of Education, Youth and Sports OP RDI programme and, in the follow-up sustainability stage, supported through CENTEM PLUS (LO1402) by financial means from the Ministry of Education, Youth and Sports under the National Sustainability Programme I. The research leading to these results has received funding from the European Union's Seventh Framework Programme (FP7/ 2007-2013) for Fuel Cell and Hydrogen Joint Technology Initiative under Grant 303446 (IMPALA).

Open Access This article is distributed under the terms of the Creative Commons Attribution 4.0 International License (http:// creativecommons.org/licenses/by/4.0/), which permits unrestricted use, distribution, and reproduction in any medium, provided you give appropriate credit to the original author(s) and the source, provide a link to the Creative Commons license, and indicate if changes were made.

\section{References}

1. Zamel, N., Xianguo, L.: Effective transport properties for polymer electrolyte membrane fuel cell-with a focus on the gas diffusion layer. Prog. Energy Combust. Sci. 39, 111-146 (2013)

2. Bazylak, A.: Liquid water visualization in PEM fuel cell: a review. Int. J. Hydrog. Energy 39, 3845-3857 (2009)

3. Chen, G., Zhang, G., Guo, L., Liu, H.: Systematic study on the functions and mechanisms of microporous layer on water transport in proton exchange membrane fuel cell. Int. J. Hydrog. Energy 41, 5063-5073 (2016)

4. Owejan, J.P., Trabold, T.A., Jacobson, D.L., Arif, M., Kandlikar, S.G.: Effects of flow field and diffusion layer on water accumulation in a PEM fuel cell. Int. J. Hydrog. Energy 32, 4489-4502 (2007)

5. Kandlikar, S.G., Garofalo, M.G., Lu, Z.: Water management in a PEMFC: water transport mechanism and material degradation in gas diffusion layers. Fuel Cells 11, 814-823 (2011)

6. Ismail, M.S., Ingham, D.B., Hughes, K.J., Ma, L., Pourkashanian, M.: Effective diffusivity of polymer electrolyte fuel cell gas diffusion layers: an overview and numerical study. Int. J. Hydrog. Energy 40, 10994-11010 (2015)

7. Gu-Gon, P., Sohn, Y.-J., Yang, T.-H., Yoon, Y.-G., Lee, W.-Y., Kim, C.-S.: Effect of PTFE contents in the gas diffusion media on the performance of PEMFC. J. Power Sources 131, 182-187 (2004) 
8. Qi, Z., Kaufman, A.: Improvement of water management by a microporous sublayer for PEM fuel cells. J. Power Sources 109, 38-46 (2002)

9. Cho, J., Ha, T., Park, J., Kim, H.-S., Min, K., Lee, E., Jyoung, J.Y.: Analysis of transient response of a unit proton-exchange membrane fuel cell with a degraded gas diffusion layer. Int. J. Hydrog. Energy 36, 6090-6098 (2011)

10. Schulze, M., Wagner, N., Kaz, T., Friedrich, K.A.: Combined electrochemical and surface analysis investigation of degradation processes in polymer electrolyte membrane fuel cells. Electrochim. Acta 52, 2328-2336 (2007)

11. Park, S., Lee, J.-W., Popov, B.N.: A review of gas diffusion layer in PEM fuel cell: materials and designs. Int. J. Hydrog. Energy 37, 5850-5865 (2012)

12. Lee, C., Merida, W.: Gas diffusion layer durability under steadystate and freezing conditions. J. Power Sources 164, 141-153 (2007)

13. Pullor Kuttanikkad, S., Prat, M., Pauchet, J.: Pore-network simulations of two-phase flow in a thin porous layer of mixed wettability: application to water transport in gas diffusion layers of proton exchange membrane fuel cells. J. Power Sources 196, 1145-1155 (2011)

14. El Hannach, M., Prat, M., Pauchet, J.: Pore network model of the cathode catalyst layer of proton exchange membrane fuel cells: analysis of water management and electrical performance. Int. J. Hydrog. Energy 37, 18996-19006 (2012)

15. Ceballos, L., Prat, M.: Slow invasion of a fluid from multiple inlet sources in a thin porous layer: influence of trapping and wettability. Phys. Rev. E 87, 043005 (2013)

16. Chen, G., Zhang, H., Ma, H., Zhong, H.: Electrochemical durability of gas diffusion layer under simulated proton exchange membrane fuel cell conditions. Int. J. Hydrog. Energy 34, 8185-8192 (2009)

17. Borup, R.L., Meyers, J., Pivovar, B., Kim, Y.S., Mukundan, R., Garland, N., Myers, D., Wilson, M., Garzon, F., Wood, D., Zelenay, P., More, K., Stroh, K., Zawodzinski, T., Boncella, J., McGrath, J.E., Inaba, M., Miytake, K., Hori, M., Ota, K., Ogumi, Z., Miyata, S., Nishikata, A., Siroma, Z., Uchimoto, Y., Yasuda, K., Kimijima, K.-I., Iwashita, N.: Scientific aspects of polymer electrolyte fuel cell durability and degradation. Chem. Rev. 107, 3904-3951 (2007)

18. Jing, M., Jiang, L., Wang, S., Jing, F., Sun, G.: Application of FTIR in direct methanol fuel cells-quantitative analysis of PTFE in gas diffusion layers. Int. J. Hydrog. Energy 38, 7957-7963 (2013)

19. Schulze, M., Gültzow, E., Schönbauer, S., Knöri, T., Reissner, R.: Segmented cells as tool for development of fuel cells and error prevention/prediagnostic in fuel cell stacks. J. Power Sources 173, 19-27 (2007)

20. Lin, R., Sander, H., Gülzow, E., Friedrich, A.K.: Investigation of locally resolved current density distribution of segmented PEM fuel cells to detect malfunctions. ECS Trans. 26, 229-236 (2010)

21. Zhang, J., Yin, G.P., Wang, Z.-B., Lai, Q.-Z., Cai, K.-D.: Effects of hot pressing conditions on the performances of MEAs for direct methanol fuel cells. J. Power Sources 165, 73-81 (2007)
22. Pauchet, J., Prat, M., Schott, P., Pulloor, Kuttanikkad S.: Performance loss of proton exchange membrane fuel cell due to hydrophobicity loss in gas diffusion layer: analysis by multiscale approach combining pore network and performance modelling. Int. J. Hydrog. Energy 37, 1628-1641 (2012)

23. Rangel-Hernandez, V.H., Damian-Ascencio, C., Juarez-Robles, D., Galegos-Munoz, A., Zaleta-Aguilar, A., Plascencia-Mora, H.: Entropy generation analysis of a proton exchange membrane fuel cell (PEMFC) with a Fermat spiral as a flow distributor. Heat transfer phenomena and application. Intech, Rijeka (2012). ISBN 978-953-51-0815-3

24. Geske, M., Heuer, M., Heideck, G., Styczynski, Z.A.: Current density distribution mapping in PEM fuel cells as an instrument for operational measurement. Energies 3, 770-783 (2010)

25. Yoshizawa, K., Ikezoe, K., Tasaki, Y., Kramer, D., Lehmann, E.H., Scherer, G.G.: Analysis of gas diffusion layer and flow-field design in a PEMFC using neutron radiography. J. Electrochem. Soc. 155, B223-B227 (2008)

26. Mukundan, R., Davey, J.R., Rau, K., Langlois, D.A., Spernjak, D., Fairweather, J.D., Artyushkova, K., Schweiss, R., Borup, R.L.: Degradation of gas diffusion layer in PEM fuel cells during drive cycle operation. ECS Trans. 58, 919-926 (2013)

27. Xiong, Z., Liao, S., Dang, D., Tian, X., Hou, S., Liu, F., Peng, H., $\mathrm{Fu}, \mathrm{Z}$.: Enhanced water management in the cathode of an airbreathing PEMFC using a dual catalyst layer and optimizing the gas diffusion and microporous layers. Int. J. Hydrog. Energy 40 , 3961-3967 (2015)

28. Escribano, S., Blachot, J.-F., Etheve, J., Morin, A., Mosdale, R.: Characterization of PEMFC gas diffusion layers properties. J. Power Sources 156, 8-13 (2006)

29. Gigos, P.A., Faydi, Y., Meyer, Y.: Mechanical characterization and analytical modeling of gas diffusion layers under cyclic compression. Int. J. Hydrog. Energy 40, 5958-5965 (2015)

30. Gardner, C.L., Anantaraman, A.V.: Studies on ion-exchange membranes. II. Measurement of the anisotropic conductance of Nafion. J. Electroanal. Chem. 449, 209-214 (1998)

31. Shuchun, Y., Xiaojin, L., Jin, L., Sa, L., Wangting, L., Zhigang, S., Baolian, Y.: Study on hydrophobicity degradation of gas diffusion layer in proton exchange membrane fuel cells. Energy Convers. Manag. 76, 301-306 (2013)

32. Shuchun, Y., Xiaojin, L., Jin, L., Sa, L., Jinkai, H., Zhigang, S., Baolian, Y.: Study on hydrophobicity loss of the gas diffusion layer in PEMFCs by electrochemical oxidation. RSC Adv. 4, 3852-3856 (2014)

33. LaManna, J.M., Kandlikar, S.G.: Determination of effective water vapor diffusion coefficient in PEMFC diffusion layers. Int. J. Hydrog. Energy 36, 5021-5029 (2011)

\section{Publisher's Note}

Springer Nature remains neutral with regard to jurisdictional claims in published maps and institutional affiliations. 